\title{
Evaluating meso-scale change in performance of several databases of hourly surface irradiation in South-eastern Arabic Pensinsula
}

\author{
Mathilde Marchand ${ }^{1}$, Nasser Al-Azri ${ }^{2}$, Armel Ombe-Ndeffotsing ${ }^{3}$, Etienne Wey ${ }^{1}$, and Lucien Wald ${ }^{4}$ \\ ${ }^{1}$ Transvalor, Mougins, 06255, France \\ ${ }^{2}$ Sultan Qaboos University, Al Khod, 123, Oman \\ ${ }^{3}$ Total Energies Nouvelles, Paris La Défense, 92069, France \\ ${ }^{4}$ MINES ParisTech, PSL Research University, Sophia Antipolis, 06904, France
}

Correspondence to: Mathilde Marchand (mathilde.marchand@transvalor.com)

Received: 11 November 2016 - Revised: 27 January 2017 - Accepted: 31 January 2017 - Published: 8 February 2017

\begin{abstract}
The solar hourly global irradiation received at ground level estimated by the databases HelioClim3v4, HelioClim-3v5 and CAMS Radiation Service are compared to coincident measurements made in five stations in Oman and Abu Dhabi. CAMS is an abbreviation of Copernicus Atmosphere Monitoring Service. Each database describes the hour-to-hour changes in irradiation very well with correlation coefficients greater than 0.97 for all stations. Each database exhibits a tendency to underestimate the irradiation in this area; the bias is small and less than $5 \%$ of the average of the measurements in absolute value. The RMSE ranges between 70 and $90 \mathrm{Wh} \mathrm{m}^{-2}$ (11 to $16 \%$ ). This validation of the three databases for this arid region on the edge of the Meteosat coverage reveals satisfactory results. Each database captures accurately the temporal and spatial variability of the irradiance field. It is found that the three databases do not exhibit noticeable geographical changes in performances and are reliable sources to assess the SSI in this region.
\end{abstract}

\section{Introduction}

The energy received from the sun on a horizontal surface at ground level and per unit surface is called the surface solar downward irradiation (SSI). Hourly SSI is the irradiation received during one hour. The SSI plays a major role in many domains such as weather and climate (Abdel Wahab et al., 2009; Blanc et al., 2011, 2015; Lefèvre et al., 2007), ocean (Bell et al., 2009), agriculture (Bois et al., 2008a), forestry (Colombo et al., 2009), ecology (Wagner et al., 2011), oenology (Bois et al., 2008b), human health (Juzeniene et al., 2011), energy (Kenfack et al., 2009; Szabó et al., 2011), or architecture (Leloux et al., 2012; Rotar and Badescu, 2011). Current means for SSI assessment are ground-based instruments which may offer high to good quality measurements if well attended but are too few to offer the coverage needed in space and time. Global meteorological reanalyses exist that go several decades back in time. It has, however, been shown that the SSI data from these have significantly lower qual- ity than the SSI data from satellite-based databases (Boilley and Wald, 2015). Accurate assessments of the SSI can be made from satellite images which may supplement radiometric measurements (Lefèvre et al., 2014; Wagner et al., 2011).

Several databases have been constructed from satellite images that contain $15 \mathrm{~min}$ SSI. Among them, are the HelioClim-3 databases (version 4 and version 5) and the CAMS Radiation Service (CAMS-Rad) detailed hereafter, where CAMS stands for Copernicus Atmosphere Monitoring Service. These databases are accessed on-line by several hundreds of users each year (Thomas et al., 2016a). Many validations were performed and are still being performed to supply users with the most complete knowledge of the accuracy of each database. Such validations are made by comparing satellite-derived estimates against coincident qualified ground measurements for various climates to better understand the strengths and weaknesses of the databases. For example, joint validations of these three databases were performed for nine stations belonging to the Baseline Surface 


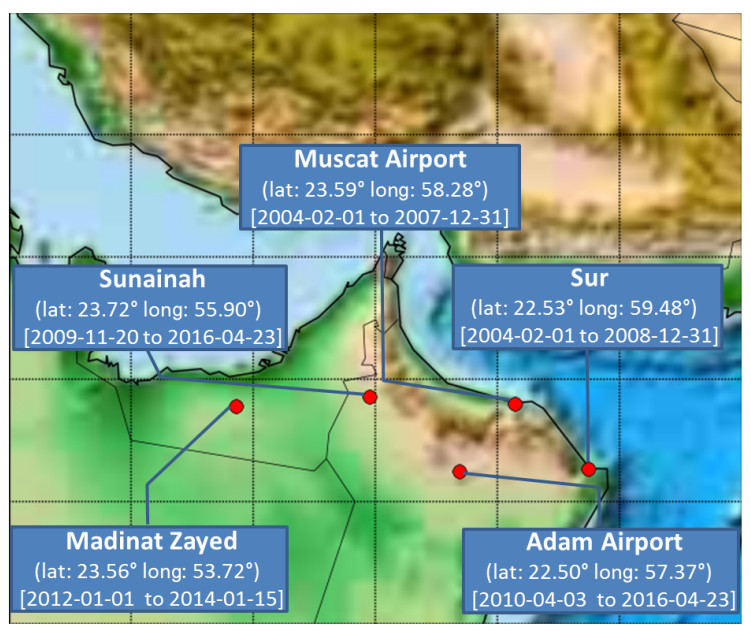

Figure 1. Geographical locations and coordinates of the five stations.

Radiation Network (BSRN) and located in various climates in Europe (Thomas et al., 2016b), for nine stations in Egypt (Eissa et al., 2015a), and in Brazil by Thomas et al. (2016a).

The present work contributes to this continuous effort and supports the gathering of evidence of site-specific strengths and weaknesses of the databases. It contributes to addressing the issue of the spatial consistency of errors in the retrieval of hourly global irradiation. It focuses on the South-eastern part of the Arabic Peninsula. The climate is BWh in the KöppenGeiger climate classification, i.e. an arid area with few precipitations and hot air temperatures. Additionally, the proximity of the Arabian Gulf affects the climate because of large relative humidity encountered close to the coastline.

\section{Description of measurements used for comparison and quality control}

Measurements of hourly global SSI performed at five stations were collected from the Directorate General of Meteorology of Oman for the sites Sunainah, Muscat Airport, Sur and Adam Airport, and the National Center for Meteorology and Seismology of the United Arab Emirates (UAE) for Madinat Zayed, in the period from 2004 to 2016 (Fig. 1). The sites have below $150 \mathrm{~m}$ above average sea level, except Sunainah (257 m) and Adam Airport (328 m).

Measurements were quality-checked following the WMO procedure (1981). The procedure applied to flag suspicious or erroneous measurements is described in detail in Korany et al. (2016). Non plausible values, i.e. values exceeding extremely rare limits and physically possible limits, were rejected. The lowest values can be noise and are therefore insignificant. In order to remove them, a threshold was set to 1.5 times the relative uncertainty given by WMO (2008) for measurements of good to moderate quality (13\%), i.e. approximately $50 \mathrm{Wh} \mathrm{m}^{-2}$. Only measurements exceeding this threshold were kept; in this way, there was $0.3 \%$ chance of having insignificant very low values. Eventually, a visual analysis was performed to remove outliers.

\section{The family of Heliosat methods, the HelioClim databases and the CAMS Radiation Service}

The Heliosat family is a series of methods whose aim is to convert images acquired by satellites into fields of SSI. The original method was published by Cano et al. (1986). It assumes that the appearance of a cloud over a pixel results in an increase of radiance in visible imagery. It examines the change between the radiance that should be observed in cloud-free conditions and that currently observed; this change is quantified by a cloud index. The extinction of the downwelling radiation by the atmosphere is related to this cloud index. Of interest here, is the follow-up Heliosat2 (Rigollier et al., 2004) which yields more accurate results and is easier to implement. Espinar et al. (2009) analysed the influences of uncertainties of inputs on the outcomes of Heliosat-2.

The Meteosat series of geostationary meteorological satellites have been initiated by the European Space Agency and are currently operated by Eumetsat, a European agency comprising the national weather offices. They provide synoptic views of Europe, Africa and Atlantic Ocean. Images are acquired in several spectral channels from which the presence of clouds and their effects on radiation may be deduced.

Within the HelioClim project (Blanc et al., 2011), images of the first generation of the Meteosat series were processed with the Heliosat- 2 method to create and update the HelioClim-1 database containing daily SSI (Lefèvre et al., 2007). The HelioClim-1 database has been promoted to Data Collection of Open Resources for Everyone (Data-CORE) by the GEOSS (Global Earth Observation System of Systems) (Lefèvre et al., 2014). The GEOSS Data-CORE is a distributed pool of documented data sets with full, open and unrestricted access. Heliosat- 2 was further adapted to processing of images from the second generation of the Meteosat satellites (Cros et al., 2006). Since 2004, Meteosat images are acquired every $15 \mathrm{~min}$ and routinely processed to update the HelioClim-3 database containing 15 min SSI, abbreviated hereafter in HC3. Access to the HelioClim databases is given by the SoDa Service (www.soda-pro.com) (Gschwind et al., 2006).

A clear-sky model is a model that predicts the SSI that should be observed at a given site any time in cloud-free conditions. The Heliosat-2 method combines the cloud index with the ESRA clear sky model (European Solar Radiation Atlas, Page et al., 2001). This model is detailed in Rigollier et al. (2000) with corrections in Geiger et al. (2002). Main inputs are the reflectance of the ground that originates from the Meteosat images themselves (Moussu et al., 1989; Rigollier et al., 2004) and the Linke turbidity factor which accounts for 
the optical state of the cloudless atmosphere (Remund et al., 2003). Post-processing layers are applied when a request for a time-series of SSI is launched to bring improvements and corrections to the original $\mathrm{HC} 3$ database. For example, the SSI stored in HC3 is modulated to account for the actual elevation of the required location or the shadowing effect of the horizon. In order to avoid several re-processings of the whole set of images dating back to 2004, improvements in HC3 are made by changes in the post-processing layers, leaving the original database unchanged. $\mathrm{HC} 3 \mathrm{v} 4$ is the most advanced version of $\mathrm{HC} 3$ using the ESRA model.

Building on the approximation of Oumbe et al. (2014) for decoupling the effects of the clouds from those of the cloudless atmosphere, Qu et al. (2014) have proposed to combine $\mathrm{HC} 3 \mathrm{v} 4$ and the recent McClear clear sky model (Lefèvre et al., 2013) in an attempt to overcome the fact that the Remund's database of the Linke turbidity factor is not updated and does not take into account temporal changes in the atmosphere turbidity. McClear takes as input properties of the cloud-free atmosphere updated every $3 \mathrm{~h}$ supplied by CAMS and provides estimates of the SSI that should be observed in cloud-free conditions for any site in the world since 2004. McClear has been validated against measurements performed in the BSRN all over the world (Lefèvre et al., 2013) and in more restricted areas such as Egypt (Eissa et al., 2015a), Israel (Lefèvre and Wald, 2016) and the UAE (Eissa et al., 2015b). This combination of McClear and HC3v4 yields HC3v5. In brief, the SSI is firstly computed as in $\mathrm{HC} 3 \mathrm{v} 4$, then divided by the ESRA clear-sky SSI and eventually multiplied by the McClear clear-sky SSI.

The new Heliosat-4 method differs from the previous Heliosat methods (Qu et al., 2016) in its concept. It adopts the approximation of Oumbe et al. (2014) where the SSI is approximated by the product of the McClear SSI by a modification factor which depends on solar zenith angle, cloud properties and ground albedo. Cloud properties are provided by the German Aerospace Center (DLR), and result from the processing of the different channels of the Meteosat images by the APOLLO method (Qu et al., 2016). The ground albedo is that from Blanc et al. (2014). CAMS-Rad exploits the Heliosat-4 method to provide time series of $15 \mathrm{~min}$ SSI, starting in 2004. It can be accessed by the Copernicus web site (https://atmosphere.copernicus.eu) or the SoDa web site.

\section{Validation against the measurements and results}

Coincident HC3v4, HC3v5 and CAMS-Rad estimates of hourly global SSI $G$ were obtained from the web sites for the five stations and the same periods. Also provided were the corresponding time-series of the irradiance at the top of atmosphere on horizontal: $E_{0}$, from which one may compute the clearness index: $K_{T}$ :

$K_{T}=\mathrm{G} / E_{0}$,

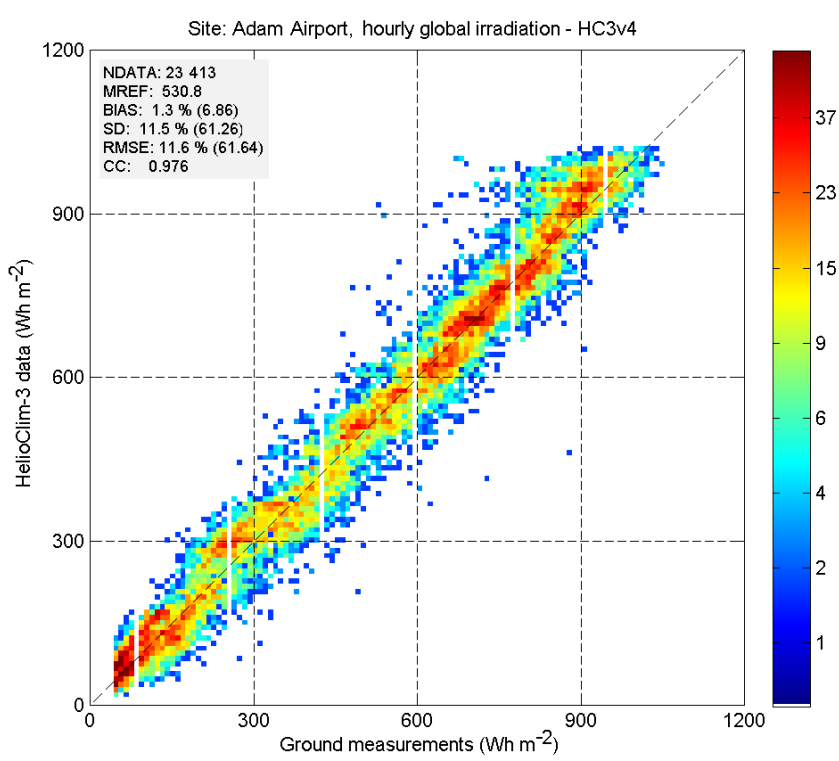

Figure 2. 2-D histogram between in situ measurements and HC3v4. Mean observed value, bias, standard-deviation and correlation coefficient are reported.

Validation follows the ISO (International Organization for Standardization) standard (1995) where the deviations are computed by subtracting measurements for each instant from the databases estimates. Deviations were summarized by the bias, the root mean square error (RMSE), and the correlation coefficient. Relative values are expressed with respect to the average of the measurements. The validation of $K_{T}$ was also included.

The 2-D histograms of measured and estimated values are presented for Adam Airport (Figs. 2, 3 and 4). Red, respectively dark blue, dots correspond to regions with great, respectively very low, densities of samples. The plots also present the number of samples, the mean observed value, the bias, the RMSE, the correlation coefficient (CC) and the $1: 1$ line $(y=x)$. Points are aligned along the $1: 1$ line with a limited scattering. The bias is $7 \mathrm{Wh} \mathrm{m}^{-2}$ and the RMSE is $61 \mathrm{Wh} \mathrm{m}^{-2}$. The temporal changes in $G$ are well reproduced by $\mathrm{HC} 3 \mathrm{v} 4$ as demonstrated by the very large correlation coefficient: 0.976 . One may note an overestimation of the greatest $G$.

Figure 3 does not exhibit such an overestimation likely due to the better estimation of cloud-free SSI by McClear compared to ESRA. The points are well aligned though an overall underestimation is visible. The bias and RMSE are respectively -20 and $66 \mathrm{Wh} \mathrm{m}^{-2}$. The correlation coefficient is very large: 0.974 . The bias for CAMS-Rad is very small: $1 \mathrm{Wh} \mathrm{m}^{-2}$ (Fig. 4) and the RMSE is similar to those for HC3v4 and v5: $68 \mathrm{Wh} \mathrm{m}^{-2}$. The dots are well aligned and the scattering is fairly symmetrical with respect to the $1: 1$ line. Like the others, the correlation coefficient is very large: 0.972 . 


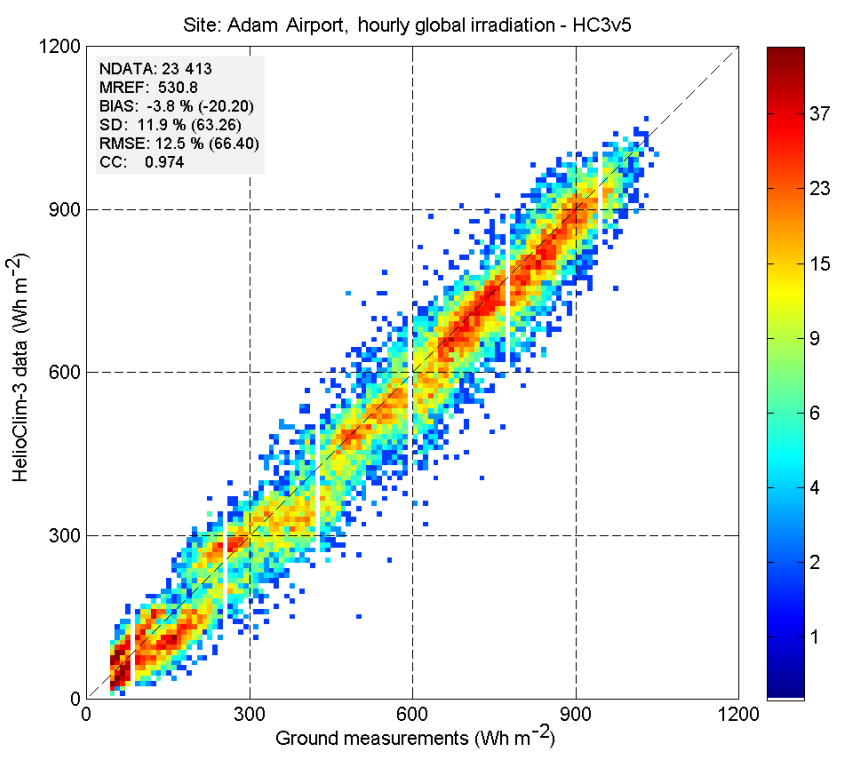

Figure 3. 2-D histogram between in situ measurements and HC3v5. Mean observed value, bias, standard-deviation and correlation coefficient are reported.

Tables 1-4 show the results for $G$ and $K_{T}$. The means of $G$ (Table 1, approximately $550 \mathrm{Wh} \mathrm{m}^{-2}$ ) and $K_{T}$ (Table 3, approximately 0.65 ) are large: the atmosphere is very often clear and not turbid.

In order to assess the ability of a database to depict spatial variability, the correlation coefficient between time-series of measurements was computed for each pair of stations for $G$ (Table 5). The same procedure is applied to each database. Table 5 gives the correlation matrix of $G$ between stations. Upper right part of the matrix (in bold) is for measurements, and lower left part is for databases. For a given database, the closer the coefficients of the lower part to those of the upper part, the more accurately this database depicts the variability in space. This was performed only for stations covering the same period of time and for coincident measurements: Sunainah and Adam Airport for the period 2010-2015 on the one hand, and Sur and Muscat Airport for 2004-2007 on the other hand. The geodetic distance between these stations is approximately 200 and $170 \mathrm{~km}$ respectively.

\section{Discussion}

The correlation coefficient in $G$ is large for all stations and all databases: it usually exceeds 0.97 , meaning that the variability in time of the measurements expressed as a variance is well reproduced by each database. As a whole, HC3v5 exhibits the greatest correlation coefficients, then $\mathrm{HC} 3 \mathrm{v} 4$, then CAMS-Rad. These large correlation coefficients are partly due to the fact that the daily course of the sun and seasonal effects are well reproduced by models leading to a de facto correlation between observations and estimates of SSI hiding

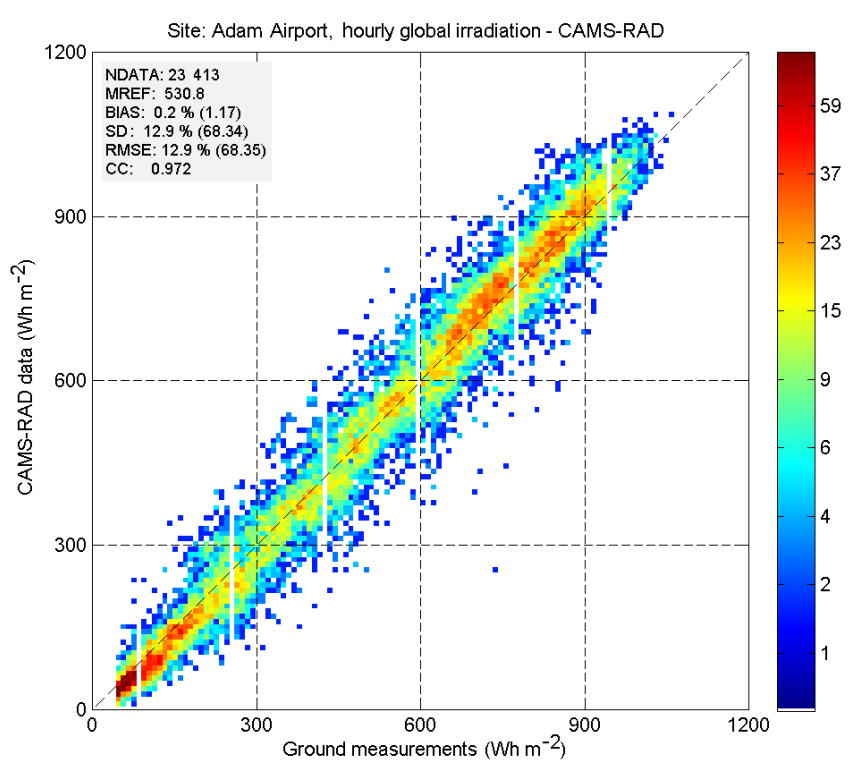

Figure 4. 2-D histogram between in situ measurements and CAMSRad. Mean observed value, bias, standard-deviation and correlation coefficient are reported.

potential weaknesses of models. $K_{T}$ is a strict indicator of the ability of the model to estimate the optical state of the atmosphere as its dependency with the solar zenith angle is less pronounced than the SSI. Hence, the correlation coefficient for $K_{T}$ is less than for $G$ : it ranges between 0.73 and 0.86 . It can be concluded that each database reproduces fairly well the variation from hour-to-hour of the measured clearness index. The hierarchy in the databases is different: CAMS-Rad performs best, then $\mathrm{HC} 3 \mathrm{v} 5$, then $\mathrm{HC} 3 \mathrm{v} 4$.

The bias for $G$ is often small and less than $5 \%$ in absolute value (Tables 1 and 2), and $7 \%$ in $K_{T}$ (Tables 3 and 4). It is negative in all cases but one, meaning that all databases underestimate $G$. Though the periods of measurements are not the same, there is sufficient overlap to conclude that there is no major change in bias from one station to another for a given database. Madinat Zayed is an exception for HC3v4 and $\mathrm{HC} 3 \mathrm{v} 5$; the bias is very large $-59 \mathrm{Wh} \mathrm{m}^{-2}(-11 \%)$ and $-50 \mathrm{Wh} \mathrm{m}^{-2}(-9 \%)$. On the contrary, the bias in Madinat Zayed for CAMS-Rad is similar to that of the other stations. Accordingly, the cause of the large bias in $\mathrm{HC} 3 \mathrm{v} 4$ and $\mathrm{HC} 3 \mathrm{v} 5$ is likely related to the specifics of the method Heliosat-2. It is known that the uncertainty on the ground albedo may have a great impact on the SSI in Heliosat-2 (Espinar et al., 2009; Lefèvre et al., 2007). As a whole, the surroundings of the stations in Oman are darker than the highly reflective sand dunes surrounding Madinat Zayed site. This may partly explain the special case of Madinat Zayed as an error here has a greater influence than a similar error in the other stations. In addition, Oumbe et al. (2013) showed an overestimation of the aerosol optical depth by CAMS which yields an under- 
Table 1. Global hourly SSI. Number of coincident data, mean of measurements, bias and RMSE and correlation coefficient for HC3v4. RMSE: root mean square error.

\begin{tabular}{lrrrrr}
\hline & $\begin{array}{r}\text { Number of } \\
\text { pairs }\end{array}$ & $\begin{array}{r}\text { Mean of the measurements } \\
\left(\mathrm{Wh} \mathrm{m}^{-2}\right)\end{array}$ & $\begin{array}{r}\text { Bias }\left(\mathrm{Wh} \mathrm{m}^{-2}\right) \text { and } \\
\text { relative value }\end{array}$ & $\begin{array}{r}\text { RMSE }\left(\mathrm{Wh} \mathrm{m}^{-2}\right) \\
\text { and relative value }\end{array}$ & $\begin{array}{r}\text { Correlation } \\
\text { coefficient }\end{array}$ \\
\hline Sunainah & 25790 & 522.5 & $-6(-1 \%)$ & $68(13 \%)$ & 0.972 \\
Muscat Airport & 15636 & 565.3 & $-20(-4 \%)$ & $77(14 \%)$ & 0.969 \\
Madinat Zayed & 7374 & 551.8 & $-59(-11 \%)$ & $92(17 \%)$ & 0.972 \\
Sur & 18749 & 559.4 & $-11(-2 \%)$ & $73(13 \%)$ & 0.970 \\
Adam Airport & 23413 & 530.8 & $7(1 \%)$ & $62(12 \%)$ & 0.976 \\
\hline
\end{tabular}

Table 2. Global hourly SSI. Bias, RMSE and correlation coefficient for HC3v5 and CAMS-Rad. RMSE: root mean square error.

\begin{tabular}{|c|c|c|c|c|c|c|}
\hline & \multicolumn{3}{|c|}{$\mathrm{HC} 3 \mathrm{v} 5$} & \multicolumn{3}{|c|}{ CAMS-Rad } \\
\hline & $\operatorname{Bias}\left(\mathrm{Wh} \mathrm{m}^{-2}\right)$ & $\operatorname{RMSE}\left(\mathrm{Wh} \mathrm{m}^{-2}\right)$ & Corr. coeff. & $\operatorname{Bias}\left(\mathrm{Wh} \mathrm{m}^{-2}\right)$ & $\operatorname{RMSE}\left(\mathrm{Wh} \mathrm{m}^{-2}\right)$ & Corr. coeff. \\
\hline Sunainah & $-7(-1 \%)$ & $68(13 \%)$ & 0.975 & $-2(0 \%)$ & $73(14 \%)$ & 0.969 \\
\hline Muscat Airport & $-30(-5 \%)$ & $78(14 \%)$ & 0.971 & $-30(-5 \%)$ & $82(14 \%)$ & 0.968 \\
\hline Madinat Zayed & $-50(-9 \%)$ & $89(16 \%)$ & 0.968 & $-21(-4 \%)$ & $60(11 \%)$ & 0.983 \\
\hline Sur & $-41(-7 \%)$ & $83(15 \%)$ & 0.971 & $-30(-5 \%)$ & $90(16 \%)$ & 0.959 \\
\hline Adam Airport & $-20(-4 \%)$ & $66(13 \%)$ & 0.974 & $1(0 \%)$ & $68(13 \%)$ & 0.972 \\
\hline
\end{tabular}

Table 3. Global hourly clearness index. Number of coincident data, mean of measurements, bias and RMSE and correlation coefficient for HC3v4. RMSE: root mean square error.

\begin{tabular}{lrrrrr}
\hline & $\begin{array}{r}\text { Number of } \\
\text { pairs }\end{array}$ & $\begin{array}{r}\text { Mean of } \\
\text { the measurements }\end{array}$ & $\begin{array}{r}\text { Bias and } \\
\text { relative value }\end{array}$ & $\begin{array}{r}\text { RMSE and } \\
\text { relative value }\end{array}$ & $\begin{array}{r}\text { Correlation } \\
\text { coefficient }\end{array}$ \\
\hline Sunainah & 25790 & 0.61 & $-0.02(-3 \%)$ & $0.09(15 \%)$ & 0.791 \\
Muscat Airport & 15636 & 0.68 & $-0.03(-5 \%)$ & $0.12(18 \%)$ & 0.726 \\
Madinat Zayed & 7374 & 0.66 & $-0.08(-12 \%)$ & $0.13(20 \%)$ & 0.762 \\
Sur & 18749 & 0.65 & $-0.01(-2 \%)$ & $0.10(15 \%)$ & 0.779 \\
Adam Airport & 23413 & 0.64 & $0.01(1 \%)$ & $0.09(14 \%)$ & 0.789 \\
\hline
\end{tabular}

estimation in $G$. This may partly explain the underestimation in CAMS-Rad.

Except the case of Madinat Zayed, one may observe that for a given station, the bias varies only slightly from one database to another whether for $G$ or for $K_{T}$. This holds also for the RMSE, with the exception of Madinat Zayed; the RMSE is the same for a given station whatever the database. Conversely, for a given database, the RMSE varies only slightly from one station to another. The RMSE ranges between 70 and $90 \mathrm{Wh} \mathrm{m}^{-2}$ and is 11 to $16 \%$ of the mean of the measurements, which is very good for hourly SSI estimated from satellite imagery.

Table 6 presents the relative bias, the relative RMSE and the correlation coefficient reported by Eissa et al. (2015a) for several stations in Egypt and for the period 2004-2009, and Thomas et al. (2016b) for the BSRN site of Sede Boqer in Israel for the period 2004-2012. For a given database, one may observe a tendency to underestimation in Oman-UAE compared to Egypt and Sede Boqer: there is a tendency for increasing absolute value of bias. This yields a greater RMSE for Oman-UAE than for Egypt and Sede Boqer.

The difference in bias between these three areas with the same arid climate BWh may be party explained by the systematic errors in the ground albedo as already discussed. Another explanation may come from the fact that the sites in Oman-UAE are farther from the nadir of the Meteosat satellites and that the angles under which the space-borne sensor views these sites are greater than for Egypt or Israel. This implies a greater influence of the parallax effect and a greater size of the pixel which is approximately $5 \mathrm{~km}$ in Egypt, and $8 \mathrm{~km}$ in Oman-UAE.

If a pixel is covered by clouds, the parallax effect shifts these clouds westwards. The sensor aboard the satellite does not see exactly what is happening in the atmospheric column right above a measuring station. This contributes to the deviation between satellite-derived SSI and in situ measurements. The effect of the parallax on $G$ is more pronounced when the cloud cover is fragmented, i.e. when the spatial variability in the cloud cover is large. It is less pronounced when 
Table 4. Global hourly clearness index. Bias, RMSE and correlation coefficient for HC3v5 and CAMS-Rad. RMSE: root mean square error.

\begin{tabular}{lrrr|rrr}
\hline & \multicolumn{3}{c}{ HC3v5 } & \multicolumn{3}{c}{ CAMS-Rad } \\
\cline { 2 - 7 } & Bias & RMSE & Corr. coeff. & Bias & RMSE & Corr. coeff. \\
\hline Sunainah & $0.03(-4 \%)$ & $0.10(16 \%)$ & 0.823 & $-0.02(-3 \%)$ & $0.10(16 \%)$ & 0.834 \\
Muscat Airport & $-0.05(-7 \%)$ & $0.12(19 \%)$ & 0.748 & $-0.04(-7 \%)$ & $0.11(16 \%)$ & 0.812 \\
Madinat Zayed & $-0.07(-12 \%)$ & $0.13(21 \%)$ & 0.789 & $-0.04(-7 \%)$ & $0.10(16 \%)$ & 0.856 \\
Sur & $-0.05(-8 \%)$ & $0.11(17 \%)$ & 0.816 & $-0.04(-6 \%)$ & $0.11(18 \%)$ & 0.766 \\
Adam Airport & $-0.03(-5 \%)$ & $0.10(16 \%)$ & 0.790 & $-0.01(-2 \%)$ & $0.09(15 \%)$ & 0.844 \\
\hline
\end{tabular}

Table 5. Correlation matrix between stations for measurements of $G$ (upper right part of the matrix, in bold) and for databases (lower left part).

\begin{tabular}{lrr|rrr}
\hline$G$ HC3v4; HC3v5; CAMS-Rad & Sunainah & Adam Airport & G HC3v4; HC3v5; CAMS-Rad & Sur & Muscat Airport \\
\hline Sunainah & 1 & $\mathbf{0 . 9 5 6}$ & Sur & 1 & $\mathbf{0 . 9 4 5}$ \\
\hline & 0.960 & 1 & & 0.961 & 1 \\
Adam Airport & 0.959 & & Muscat Airport & 0.960 & 0.964 \\
\hline
\end{tabular}

Table 6. Relative bias, relative RMSE and correlation coefficient reported by Eissa et al. (2015a), Thomas et al. (2016b) and this study.

\begin{tabular}{|c|c|c|c|c|c|c|c|c|c|}
\hline & \multicolumn{3}{|c|}{$\mathrm{HC} 3 \mathrm{v} 4$} & \multicolumn{3}{|c|}{$\mathrm{HC} 3 \mathrm{v} 5$} & \multicolumn{3}{|c|}{ CAMS-Rad } \\
\hline & Bias & RMSE & Correl. coeff. & Bias & RMSE & Correl. coeff. & Bias & RMSE & Correl. coeff. \\
\hline Egypt & -9 to $2 \%$ & 7 to $14 \%$ & 0.820 to 0.948 & -3 to $4 \%$ & 7 to $12 \%$ & 0.868 to 0.948 & NA & NA & NA \\
\hline Sede Boqer & $-7 \%$ & $13 \%$ & 0.982 & $-4 \%$ & $12 \%$ & 0.984 & $0 \%$ & $12 \%$ & 0.974 \\
\hline Oman UAE & -11 to $1 \%$ & 14 to $20 \%$ & 0.969 to 0.972 & -9 to $-1 \%$ & 16 to $21 \%$ & 0.968 to 0.975 & -5 to $0 \%$ & 15 to $18 \%$ & 0.959 to 0.983 \\
\hline
\end{tabular}

NA: not available.

the cloud cover is homogeneous or when the sky is clear, because a shift of homogeneous conditions has a small impact. A larger pixel increases the chance to observe clouds. Though clouds are not very frequent as shown by the large mean value of $K_{T}$, they are not absent and a patchwork of small broken clouds such as cumuli over a large pixel may be interpreted by the Heliosat- 2 and Heliosat- 4 methods as a large thin cloud. This may contribute to the deviation. In addition, a greater chance to observe clouds means also a greater chance to have a noticeable parallax effect.

While the location of Brazilian sites is also on the very edge of the Meteosat field-of-view, similarly to Oman and UAE sites but with opposite sign in latitude and longitude, the relative bias observed for Brazil (Thomas et al., 2016a) differs from that in Oman and UAE. It is between -3 and $13 \%$ for $\mathrm{HC} 3 \mathrm{v} 4,-3$ to $7 \%$ for $\mathrm{HC} 3 \mathrm{v} 5$, and 2 to $16 \%$ for CAMS-Rad. It is most often positive and close to $0 \%$ for HC3v4 and HC3v5, and always positive for CAMS-Rad. There is an overestimation in Brazil and underestimation in Oman and UAE. The difference in the influence of the parallax effect may be due to the difference in cloud cover and in type of clouds: there are more sunny days in Oman and UAE than in Brazil, and the cloud cover is more scattered.
The correlation between measurements made at Sunainah and Adam Airport, and Sur and Muscat Airport is large in both cases: 0.956 and 0.945 (Table 5). The correlation coefficients of the three databases are close: approximately 0.96 . Hence, one may conclude that the spatial variability of the SSI within each pair of stations is well reproduced by each database. One may note a slight overestimation of the spatial correlation by each database. This can be partly explained by the coarse spatial and temporal resolutions of several inputs to Heliosat-2 and Heliosat-4 methods. CAMS products on aerosols and total content in water vapour and ozone are available every $3 \mathrm{~h}$. Their spatial resolution is approximately $120 \mathrm{~km}$ along a longitude before 2014 and $80 \mathrm{~km}$ after 2014 . As for the Linke turbidity factor input to the ESRA model, there is one value per calendar month and its variability in space is fairly smooth. This spatially smooth variability of the inputs increases the spatial correlation. A similar conclusion was reached by Lefèvre and Wald (2016) in cloud-free conditions with stations located approximately $100 \mathrm{~km}$ apart in similar arid climate.

The group composed of Sur and Muscat Airport is close to the coastline and exhibits more negative bias than the group composed of Sunainah and Adam Airport which are more inland. This cannot be explained by the increase of parallax 
effect as the viewing angles are very similar for all stations. The probable reason should be found in local weather due to the temperature gradients between land and sea with effects on clouds, aerosols, and water vapour. These effects cannot be accurately observed because of the low spatial resolution of the inputs to the Heliosat- 2 and Heliosat- 4 methods, the best resolution being $8 \mathrm{~km}$.

\section{Conclusions and perspectives}

This paper presents a comparison of three satellite-derived radiation databases against the measurements of 5 stations in Oman and Abu Dhabi. A great deal of attention has been paid to the quality of the measurements prior to the comparison.

It was found that the three databases reproduce the hourto-hour changes in SSI very well with correlation coefficients greater than 0.97 for all stations. Each database exhibits a tendency to underestimate the SSI in this area. With the exception of Madinat Zayed (Abu Dhabi) for the HC3 databases, the bias is small and less than $5 \%$ in absolute value. There is no major change in bias from one station to another for a given database. Conversely, and except Madinat Zayed, it is found that for a given station, the bias varies only slightly from one database to another whether for the SSI or the clearness index.

This is also true for the RMSE: it is the same for a given station whatever the database, and conversely, for a given database, it varies only slightly from one station to another. The RMSE ranges between 70 and $90 \mathrm{Wh} \mathrm{m}^{-2}$ and is 11 to $16 \%$ of the mean of the measurements, which is very good for hourly SSI estimated from satellite imagery. Performances are still far from WMO standards: $95 \%$ of the deviations less than $20 \%$ for data of moderate quality (WMO, 2008).

Despite the identified drawbacks, this validation of the three databases for this arid region which is on the edge of the Meteosat coverage reveals satisfactory results. The three databases capture accurately the temporal and spatial variability of the irradiance field. It is found that the three databases do not exhibit noticeable geographical changes in performances and are reliable sources to assess the SSI in this region.

The present work is a contribution to the continuous effort of validation of the three databases to evidence site-specific strengths and weaknesses of the databases. It enables a better knowledge of the capacity of these databases in estimating the SSI.

\section{Data availability}

Station data for surface solar irradiance were received from the Directorate General of Meteorology of Oman and the National Center for Meteorology and Seismology of the United Arab Emirates after writing a request. Time-series of CAMS-
Rad data may be downloaded for free after registration at the Copernicus CAMS web site (https://atmosphere.copernicus. eu, CAMS, 2016) or the SoDa web site (www.soda-pro.com, SoDa, 2016). The output comprises the irradiation at the top of atmosphere. Time-series of HelioClim-3v4 or HelioClim3v5 data may be downloaded from the SoDa web site (www. soda-pro.com) managed by the company Transvalor. Data is available to anyone for free for years 2004-2006 as a GEOSS Data-CORE (GEOSS Data Collection of Open Resources for Everyone) and for-pay for the most recent years with charge depending on requests and requester. The output comprises the irradiation at the top of atmosphere. The time-series for the stations listed in this article are available for free in CSV format by request to Mathilde Marchand.

Competing interests. The authors declare that they have no conflict of interest.

Acknowledgements. The authors thank the Directorate General of Meteorology of Oman and the National Center for Meteorology and Seismology of the United Arab Emirates for providing measurements of solar radiation. The authors thank the two anonymous reviewers whose comments greatly help in improving the quality of the text. The research leading to these results has been partly undertaken within the Copernicus Atmosphere Monitoring Service (CAMS) of the European Union.

Edited by: S.-E. Gryning

Reviewed by: two anonymous referees

\section{References}

Abdel Wahab, M., El-Metwally, M., Hassan, R., Lefèvre, M., Oumbe, A., and Wald, L.: Assessing surface solar irradiance in Northern Africa desert climate and its long-term variations from Meteosat images, Int. J. Remote Sensing, 31, 261-280, 2009.

Bell, M. J., Lefebvre, M., Le Traon, P. Y., Smith, N., and WilmerBecker, K.: GODAE, The global ocean data assimilation experiment, Oceanography, 22, 14-21, 2009.

Blanc, P., Gschwind, B., Lefèvre, M., and Wald, L.: The HelioClim project: Surface solar irradiance data for climate applications, Remote Sensing, 3, 343-361, doi:10.3390/rs3020343, 2011.

Blanc, P., Gschwind, B., Lefèvre, M., and Wald, L.: Twelve monthly maps of ground albedo parameters derived from MODIS data sets, In Proceedings of IGARSS 2014, held 13-18 July 2014, Québec, Canada, USBKey, 3270-3272, 2014.

Blanc, P., Coulaud, C., and Wald, L.: Yearly changes in surface solar radiation in New Caledonia, Adv. Sci. Res., 12, 1-4, doi:10.5194/asr-12-1-2015, 2015.

Boilley, A. and Wald, L.: Comparison between meteorological reanalyses from ERA-Interim and MERRA and measurements of daily solar irradiation at surface, Renew. Energ., 75, 135-143, doi:10.1016/j.renene.2014.09.042, 2015.

Bois, B., Pieri, P., Van Leeuwen, C., Wald, L., Huard, F., Gaudillere, J.-P., and Saur, E.: Using remotely sensed solar radiation data for 
reference evapotranspiration estimation at a daily time step, Agr. Forest Meteorol., 148, 619-630, 2008a.

Bois, B., Wald, L., Pieri, P., Van Leeuwen, C., Commagnac, L., Chery, P., Christen, M., Gaudillere, J.-P., and Saur, E.: Estimating spatial and temporal variations in solar radiation within Bordeaux winegrowing region using remotely sensed data, International Journal of Vine and Wine Sciences, 42, 15-25, 2008b.

CAMS: Surface solar radiation data, available at: https:// atmosphere.copernicus.eu, last access: 13 October 2016.

Cano, D., Monget, J. M., Albuisson, M., Guillard, H., Regas, N., and Wald, L.: A method for the determination of the global solar radiation from meteorological satellites data, Sol. Energy, 37, 31-39, 1986.

Colombo, R., Busetto, L., Migliavacca, M., Meroni, M., Della Torre, C., Tagliaferri, A., Grassi, G., and Seufert, G.: Modelling carbon cycle of agro-forest ecosystems in Lombardy (Italy), Forest@, 6, 277-288, 2009.

Cros, S., Albuisson, M., and Wald, L.: Simulating Meteosat7 broadband radiances at high temporal resolution using two visible channels of Meteosat-8, Sol. Energy, 80, 361-367, doi:10.1016/j.solener.2005.01.012, 2006.

Eissa, Y., Korany, M., Aoun, Y., Boraiy, M., Abdel Wahab, M., Alfaro, S., Blanc, P., El-Metwally, M., Ghedira, H., and Wald, L.: Validation of the surface downwelling solar irradiance estimates of the HelioClim-3 database in Egypt, Remote Sensing, 7, 92699291, doi:10.3390/rs70709269, 2015a.

Eissa, Y., Munawwar, S., Oumbe, A., Blanc, P., Ghedira, H., Wald, L., Bru, H., and Goffe, D.: Validating surface downwelling solar irradiances estimated by the McClear model under cloudfree skies in the United Arab Emirates, Sol. Energy, 114, 17-31, doi:10.1016/j.solener.2015.01.017, 2015b.

Espinar, B., Ramírez, L., Polo, J., Zarzalejo, L. F., and Wald, L.: Analysis of the influences of uncertainties in input variables on the outcomes of the Heliosat-2 method, Sol. Energy, 83, 17311741, doi:10.1016/j.solener.2009.06.010, 2009.

Geiger, M., Diabaté, L., Ménard, L., and Wald, L.: A web service for controlling the quality of measurements of global solar irradiation, Sol. Energy, 73, 475-480, doi:10.1016/S0038092X(02)00121-4, 2002.

Gschwind, B., Ménard, L., Albuisson, M., and Wald, L.: Converting a successful research project into a sustainable service: the case of the SoDa Web service, Environ. Modell. Softw., 21, 15551561, doi:10.1016/j.envsoft.2006.05.002, 2006.

ISO Guide to the Expression of Uncertainty in Measurement, first edition, International Organization for Standardization, Geneva, Switzerland, 1995.

Juzeniene, A., Brekke, P., Dahlback, A., Andersson-Engels, S., Reichrath, J., Moan, K., Holick, M. F., Grant, W. B., and Moan, J.: Solar radiation and human health, Rep. Prog. Phys., 74, 066701, doi:10.1088/0034-4885/74/6/066701, 2011.

Kenfack, J., Neirac, F. P., Tatietse, T. T., Mayer, D., Fogue, M., and Lejeune, A.: Microhydro-PV-hybrid system: Sizing a small hydro-PV-hybrid system for rural electrification in developing countries, Renew. Energ., 34, 2259-2263, 2009.

Korany, M., Boraiy, M., Eissa, Y., Aoun, Y., Abdel Wahab, M. M., Alfaro, S. C., Blanc, P., El-Metwally, M., Ghedira, H., Hungershoefer, K., and Wald, L.: A database of multi-year (2004-2010) quality-assured surface solar hourly irradiation measurements for the Egyptian territory, Earth Syst. Sci. Data, 8, 105-113, doi:10.5194/essd-8-105-2016, 2016.

Lefèvre, M. and Wald, L.: Validation of the McClear clear-sky model in desert conditions with three stations in Israel, Adv. Sci. Res., 13, 21-26, doi:10.5194/asr-13-21-2016, 2016.

Lefèvre, M., Diabaté, L., and Wald, L.: Using reduced data sets ISCCP-B2 from the Meteosat satellites to assess surface solar irradiance, Sol. Energy, 81, 240-253, 2007.

Lefèvre, M., Oumbe, A., Blanc, P., Espinar, B., Gschwind, B., Qu, Z., Wald, L., Schroedter-Homscheidt, M., Hoyer-Klick, C., Arola, A., Benedetti, A., Kaiser, J. W., and Morcrette, J.-J.: McClear: a new model estimating downwelling solar radiation at ground level in clear-sky conditions, Atmos. Meas. Tech., 6, 2403-2418, doi:10.5194/amt-6-2403-2013, 2013.

Lefèvre, M., Blanc, P., Espinar, B., Gschwind, B., Ménard, L., Ranchin, T., Wald, L., Saboret, L., Thomas, C., and Wey, E.: The HelioClim-1 database of daily solar radiation at Earth surface: an example of the benefits of GEOSS Data-CORE, IEEE J. Sel. Top. Appl., 7, 1745-1753, doi:10.1109/JSTARS.2013.2283791, 2014.

Leloux, J., Narvarte, L., and Trebosc, D.: Review of the performance of residential PV systems in Belgium, Renew. Sust. Energ. Rev., 16, 178-184, 2012.

Moussu, G., Diabaté, L., Obrecht, D., and Wald, L.: A method for the mapping of the apparent ground brightness using visible images from geostationary satellites, Int. J. Remote Sens., 10, 1207-1225, 1989.

Oumbe, A., Bru, H., Eissa, Y., Marpu, P., Gherboudj, I., Ghedira, H., Blanc, P., and Wald, L.: On the improvement of MACC aerosol spatial resolution for irradiance estimation in the United Arab Emirates, ISES Solar World Congress 2013, Cancun, Mexico, 3-7 November 2013.

Oumbe, A., Qu, Z., Blanc, P., Lefèvre, M., Wald, L., and Cros, S.: Decoupling the effects of clear atmosphere and clouds to simplify calculations of the broadband solar irradiance at ground level, Geosci. Model Dev., 7, 1661-1669, doi:10.5194/gmd-71661-2014, 2014.

Page, J., Albuisson, M., and Wald, L.: The European solar radiation atlas: a valuable digital tool, Sol. Energy, 71, 81-83, doi:10.1016/S0038-092X(00)00157-2, 2001.

Qu, Z., Gschwind, B., Lefevre, M., and Wald, L.: Improving HelioClim-3 estimates of surface solar irradiance using the McClear clear-sky model and recent advances in atmosphere composition, Atmos. Meas. Tech., 7, 3927-3933, doi:10.5194/amt-73927-2014, 2014.

Qu, Z., Oumbe, A., Blanc, P., Espinar, B., Gesell, G., Gschwind, B., Klüser, L., Lefèvre, M., Saboret, L., Schroedter-Homscheidt, M., and Wald, L.: Fast radiative transfer parameterisation for assessing the surface solar irradiance: The Heliosat-4 method, Meteorol. Z., doi:10.1127/metz/2016/0781, 2016.

Rigollier, C., Bauer, O., and Wald, L.: On the clear sky model of the ESRA - European Solar Radiation Atlas - with respect to the Heliosat method, Sol. Energy, 68, 33-48, doi:10.1016/S0038092X(99)00055-9, 2000.

Rigollier, C., Lefèvre, M., and Wald, L.: The method Heliosat-2 for deriving shortwave solar radiation from satellite images, Sol. Energy, 77, 159-169, doi:10.1016/j.solener.2004.04.017, 2004.

Remund, J., Wald, L., Lefèvre, M., Ranchin, T., and Page, J.: Worldwide Linke turbidity information, Proceedings of ISES Solar 
World Congress, 16-19 June, Göteborg, Sweden, CD-ROM published by International Solar Energy Society, 2003.

Rotar, N. and Badescu, V.: Considerations on the implementation of the passive house concept in South-Eastern Europe (Romania), Int. J. Green Energy, 8, 780-794, 2011.

SoDa: Surface solar radiation data, HelioClim-3v4, HelioClim-3v5, CAMS-Radiation, available at: http://www.soda-pro.com, last access: 13 October 2016.

Szabó, S., Bódis, K., Huld, T., and Moner-Girona, M.: Energy solutions in rural Africa: mapping electrification costs of distributed solar and diesel generation versus grid extension, Environ. Res. Lett., 6, 034002, doi:10.1088/1748-9326/6/3/034002, 2011.

Thomas, C., Saboret, L., Wey, E., Blanc, P., and Wald, L.: Validation of the new HelioClim-3 version 4 real-time and short-term forecast service using 14 BSRN stations, Adv. Sci. Res., 13, 129136, doi:10.5194/asr-13-129-2016, 2016 a.
Thomas, C., Wey, E., Blanc, P., Wald, L., and Lefèvre, M.: Validation of HelioClim-3 version 4, HelioClim-3 version 5 and MACC-RAD using 14 BSRN stations, 2015 Solar Heating and Cooling, Energy Procedia, 91, 1059-1069, $2016 \mathrm{~b}$.

Wagner, R., Marxsen, J., Zwick, P., and Cox, E. J.: Central European Stream Ecosystems: The Long Term Study of the Breitenbach, New York, NY, USA, Wiley, 2011.

WMO: Technical Note No. 172, WMO-No. 554, World Meteorological Organization, Geneva, Switzerland, 121-123, 1981.

WMO: Guide to Meteorological Instruments and Methods of Observation. WMO-No. 8, Seventh Edition 2008, (rev. 2012), World Meteorological Organization, Geneva, Switzerland, 2008. 